\title{
«DEZIRES, LAYES Y CANCIONES» DE PROSAS PROFANAS
}

\author{
Miguel Ángel PÉREz Priego \\ UNED Madrid
}

\section{Resumen}

En este artículo se estudia un aspecto del interés de Rubén Darío por la literatura medieval. En este caso, se trata de la imitación de formas métricas y clases de poemas de la poesía de cancioneros del siglo XV. Se determina la fuente de información y se estudia el proceso de experimentación y recreación de aquellos poemas.

Palabras clave: Modernismo, Rubén Darío, Edad Media, Poesía de cancioneros.

\begin{abstract}
This article describes an aspect of Ruben Dario interest in medieval literature is studied. In this case, it is the imitation of metrical forms and kinds of poems Poetry songbooks of the XV century. The information source is determined and the process of experimentation and recreation of those poems are studied.
\end{abstract}

Keywords: Modernism, Ruben Dario, Middle Ages, Poetry songbooks.

Es bien conocida la atracción que sentía Rubén Darío por la Edad Media. Era un sentimiento muy de época, prácticamente compartido por toda la cultura europea de fin de siglo. Lo medieval, que hasta entonces había tenido más bien una función decorativa, pasa a ser también un ideal estético y social. Son principalmente los artistas del prerrafaelismo, como Dante Gabriel Rossetti o John Ruskin, quienes reaccionan contra el convencionalismo del arte de la civilización industrial y tratan de buscar el arte auténtico precisamente en los pintores anteriores a Rafael. 
El mundo medieval despertará un nuevo interés por sus formas artísticas, al mismo tiempo que se verá en él un baluarte frente el deterioro y alienación de la sociedad moderna. Ante el desencanto por la civilización industrial, se vuelve la atención hacia valores de aquellos siglos, cuando no había irrumpido aún en la sociedad la tecnología y la mecanización. Se vuelve la vista a los tiempos en que el modo de producción artesanal no había sido desplazado por el modo de producción industrial capitalista. Frente a los tiempos modernos, la Edad Media es evocada como una arcadia feliz, como una civilización utópica. Y así Rubén Darío podía proponer en Los Raros (1893), evocando la figura del «primitivo» Fra Domenico Cavalca y sus hagiografías:

Cuando en nuestra Bolsa el oro se cotiza duramente, cuando no hay día en que no tengamos noticia de una explosión de dinamita, de un escándalo financiero o de un baldón político, bueno será volver en espíritu a los tiempos pasados, a la Edad Media. Le Moyen Age énorme et délicat... (Darío, 1929: $160)$.

La influencia del prerrafaelismo se extendió por toda Europa. El motivo, el impulso medievalizante invadió todos los dominios artísticos. En ese fin de siglo, revistas como Blanco y Negro o la Ilustración Española y Americana publicaron numerosos artículos en defensa de la arquitectura y de la pintura medievales o sobre obras y autores literarios (sobre Alfonso X escribieron Menéndez Pelayo y Álvarez de la Braña; sobre el teatro, Enrique Serrano; sobre Ausias March, otros eruditos). La arquitectura fue invadida por el neogoticismo (como en las obras de Antoni Gaudí o de Antoni Maria Gallissà) y las artes decorativas se recargaron de formas y elementos medievales.

El motivo medieval pronto entró también en la literatura, como reacción al retoricismo oficial. Azorín, por ejemplo, explica así el entusiasmo de su generación por la sencillez y espontaneidad de Gonzalo de Berceo como reacción contra la ampulosidad y el artificio de autores como Castelar, Núñez de Arce o Echegaray. Pío Baroja, por su parte, habla también de la sensibilidad de su generación hacia la literatura medieval, en su discurso de ingreso en la Real Academia: «Nos hemos encontrado identificados con Gonzalo de Berceo, con el Poema de Fernán González, con el Romancero, con el Arcipreste de Hita, con Jorge Manrique» ${ }^{1}$.

Entre los autores de la época, fue seguramente Rubén Darío quien más se sintió atraído por la literatura medieval. En poemas juveniles, de 1881 y

1. Para más amplia documentación de estas consideraciones introductorias, remito a los estudios clásicos de Francisco López Estrada, Rubén Darío y la Edad Media, Barcelona, Planeta, 1971; y Los «Primitivos» de Manuel y Antonio Machado, Madrid, Cupsa Editorial, 1977. 
1882, comenzó ya una imitación arqueológica de la poesía medieval, tratando de remedar la lengua antigua en una especie de «fabla» totalmente inventada. Así, en un extenso poema titulado «La poesía castellana» va trazando la historia de aquella poesía remedando en cada una de las estrofas la lengua y el estilo de las sucesivas tendencias y escuelas: en I, imita la métrica irregular de la épica; en II, el alejandrino y el tetrástico monorrimo del mester de clerecía; en III, el arte mayor de Juan de Mena; en IV, imita el ritmo ágil y ligero del Santillana de las serranillas; en V, el quebrado de Jorge Manrique ${ }^{2}$.

Aparte otros escritos de ambientación medieval, en que recrea aspectos de la Edad Media germánica o comenta el «hispanofilismo» de Víctor Hugo, la obra en que Darío más se acerca a la Edad Media es el libro Prosas profanas, cuyo título tiene ya resonancias medievales y sugiere aquella mezcla de lo sacro y lo profano, tan propia del espíritu medieval. Prosas profanas se publica por primera vez en Buenos Aires, en 1896, dedicado a Carlos Vega Belgrano, amigo y promotor de la edición. Cinco años más tarde aparecerá una segunda edición, esta vez en París, 1901, en la librería de la viuda de Charles Bouret, con el mismo patrocinador ${ }^{3}$. Por entonces Darío ha realizado ya su segundo viaje a España, ahora como corresponsal de La Nación, y aquí reside hasta principios de 1900, que viaja a París para informar de la Exposición Universal. Esta segunda es una edición ampliada, con veintiún poemas más, entre los que figuran los siete que forman la sección Dezires, layes y canciones, escritos a la manera de la poesía de cancioneros del siglo XV. Estos siete poemas habían sido publicados primero en dos entregas sucesivas (cuatro y tres) en el vol. I, junio y julio, de la Revista Nueva. La revista la publicaba el periodista y editor Luis Ruiz Contreras y dio acogida en su efímera vida de apenas diez meses a los jóvenes escritores del modernismo y el 98. Son exactamente: un «Dezir a la manera de Johan de Duenyas», «Otro dezir» del mismo, un «Lay a la manera de Johan de Torres», una «Canción a la manera de Valtierra», otra

2. Cfr. «La poesía castellana», en la sección Iniciación melódica, en Rubén Darío, Poesías completas, edición de Alfonso Méndez Plancarte, Madrid, Aguilar, 1968 [1952], pp. 258-267.

3. Rubén Darío, Prosas profanas y otros poemas, Buenos Aires, Imprenta de Pablo E. Coni e Hijos, 1896; Rubén Darío, Prosas profanas y otros poemas, París-México, Librería de la Viuda de C. Bouret, 1901. Sobre el libro y su creación, puede verse Alberto Acereda, «Rubén Darío o el proceso creativo de Prosas profanas», Anales de Literatura Hispanoamericana, 28 (1999), 415-430; y ahora Julio Valle-Castillo, «Prosas profanas y otros poemas: heterogeneidad, intertexto y otros recursos», en Rubén Darío. Del símbolo a la realidad. Obra selecta, Madrid, Real Academia Española-Asociación de Academias de la Lengua Española, 2016, pp. LXXXVII-CIX, y Pedro Luis Barcia, «Prosas profanas y otros poemas», ibid., pp. 337-375. 
«Que el amor no admite cuerdas reflexiones, a la manera de Santa Fe», un «Loor a la manera del mismo» y una «Copla esparça a la manera del mismo».

Además de esa sección de siete poemas, a temas medievales dedica otros dos muy significativos, el titulado Cosas del Cid y un soneto en alejandrinos «A maestre Gonzalo de Berceo». Quiere decirse que en los cinco años que van de la primera a la segunda edición de Prosas profanas, el interés de Darío por la Edad Media se ha agrandado, seguramente gracias al fermento de sus muchas y variadas lecturas juveniles, como bibliotecario y artículos sobre Dante ${ }^{4}$. Ahora, al contacto más directo con España, parece reavivado ese interés por lo medieval, alentado también por las tendencias culturales de fin de siglo y la expansión triunfante del prerrafaelismo. No es pues solo un interés por lo medieval hispánico, de preocupación por España como los noventayochistas, sino más amplio, muy apegado también a su interés por la cultura francesa ${ }^{5}$. Esas dos tradiciones, la hispánica y la francesa, explican por ejemplo la versión del Cid que ofrece en su poema, no arrancado de la vieja gesta castellana sino del poema Le Cid de Barbey d'Aurevilly, que recrea una anécdota de la leyenda mostrándonos a un Cid muy humanizado que tiende su mano desnuda a un mendigo leproso y una niña que le ofrece como premio una rosa y un laurel. O explican el magnífico soneto a Berceo que no es sino una exaltación del verso alejandrino francés, que él mismo se encargaría de poner de moda entre los poetas modernistas. Los poemas de la sección Dezires... también responden a ese múltiple interés cultural, en este caso, inspirados en la poesía hispánica de cancionero, que hundía sus raíces en la antigua y venerable poesía provenzal.

Aunque, como se ha dicho, en esta imitación y aprovechamiento de metros medievales, Rubén no fue original y pudo seguir la moda simbolista de época, es muy significativo que elija la poesía de cancioneros, y en ella, los géneros más característicos (dezir, canción) y también más exóticos (lay, loor, esparsa), aparte de recrearse en términos técnicos como tornada y finida, todos de ilustre resonancia cortés y provenzal. La poesía de cancioneros, en definitiva, le brindaba un campo fértil y bien abonado, pues procedía de antiguas formas provenzales, cultivadas luego en las distintas cortes peninsulares de Aragón, Castilla o Navarra.

4. Véase Andrés R. Quintián, Cultura y literatura españolas en Rubén Darío, Madrid, Gredos, 1874, pp. 138-141.

5. Puede verse Juan García Única, «Un incógnito estigma: la literatura española medieval en Prosas profanas de Rubén Darío», en Ângel Esteban (Coord.), Darío a diario. Rubén y el Modernismo en las dos orillas, Granada, Universidad de Granada, 2007, pp. 71-91. 
Por los años en que Darío escribe estos poemas, de no ir directamente a los manuscritos, no se podía conocer mucha poesía de cancioneros ni leerla por ediciones modernas. Tomás Antonio Sánchez, el gran editor neoclásico de poesía medieval, había editado sólo las poesías anteriores al siglo XV, dejando la producción de ese siglo como tarea pendiente ${ }^{6}$. También quedó fallido el proyecto de un Cancionero general del siglo XV (MN13) que emprendieron hacia 1807 los bibliotecarios y académicos Juan C. Rodríguez Alamanzón, Martín Fernández Navarrete, Manuel Abella y Francisco Antonio González, que no llegó a culminarse y quedó inédito ${ }^{7}$. Eugenio de Ochoa apenas había publicado unas Rimas inéditas de don Íñigo López de Mendoza y de otros poetas del siglo XV (París, 1844). En 1851 el marqués de Pidal y el propio Ochoa editaban el Cancionero de Baena; en 1472 el Marqués de la Fuensanta del Valle y J. Sancho Rayón publicaban el Cancionero de Stúñiga, Madrid, 1872, dos de las colecciones más importantes de poesía del siglo XV. En la Biblioteca de Autores Españoles de Rivadaneyra no se editó poesía del XV, Marcelino Menéndez Pelayo comenzaba a publicar su Antología de poetas líricos ${ }^{8}$, hasta 1912 no editaría R. Foulché-Delbosc, en la Nueva Biblioteca de Autores Españoles, el Cancionero castellano del siglo XV. Faltaba por editarse, pues, mucha poesía de cancioneros. Particularmente el cancionero que llenaba el hueco entre Baena y Estúñiga, el conocido como Cancionero de Palacio. Este era el más representativo de la actividad poética cortesana entre 1437 y 1442, y reflejaba el ambiente aristocrático de la corte de Juan II de Castilla, de la corte aragonesa y de las campañas italianas de Alfonso V. Recogía unos cuatrocientos poemas, la mayoría de tema galante amoroso, obra de autores muy diversos, desde el propio rey y su condestable don Álvaro de Luna a nobles y caballeros o poetas de oficio y de más humilde extracción.

Conviene decir que este cancionero no ha sido editado completo hasta el siglo XX, en 1954 por Francisca Vendrell, en 1989 por Ana Ma Álvarez Pellitero ${ }^{9}$ y actualmente está siendo minuciosamente estudiado y analizado por el grupo de investigación que dirige Cleofé Tato en la Universidad de A Coruña,

6. Colección de poesías castellanas anteriores al siglo XV, Madrid, Antonio de Sancha, 17791790,4 vols.

7. Josep Lluís Martos, «La Real Academia Española y el Cancionero general del siglo XV: un proyecto editorial ilustrado», Boletín de la Real Academia Española, 92 (2012), 221-253.

8. Antología de poetas líricos castellanos desde la formación del idioma hasta nuestros días, Madrid, Librería de Perlado, Páez y Cía., 1890-1916, 14 vols.

9. Francisca Vendrell de Millás, El Cancionero de Palacio (Manuscrito n. 594), Barcelona, CSIC, 1945; Ana Ma Álvarez Pellitero, Cancionero de Palacio, Salamanca, Junta de Castilla y León, 1993. 
que ha producido ya varias tesis doctorales y numerosos trabajos y aportaciones críticas $^{10}$. En la época en que Darío viaja a España, lo que se conocía era una edición parcial del cancionero, una particular antología realizada por el escritor Alfonso Pérez Gómez Nieva, con el título de Colección de poesías de un Cancionero del siglo XV existente en la Biblioteca de D. Alfonso XII, publicada en Madrid, Alfredo Alonso, 1884.

Desde la publicación de Prosas profanas, venía sorprendiendo la sección de Dezires, layes y canciones y, por supuesto, se advertía su relación con la poesía de cancioneros del siglo XV. Si Unamuno, que felicitaba en carta a Darío por estos poemas, marraba algo el tiro al relacionarlos con el Cancionero de $B a e n a^{11}$, Pedro Henríquez Ureña ponía énfasis en la imitación de la poesía de cancioneros y en el puro afán de experimentar del poeta, pero se preguntaba por la fuente concreta de donde la tomaba y se extrañaba de que no fueran los grandes poetas (Mena, Santillana, los Manrique) los imitados y sí otros mucho menos importantes ${ }^{12}$. Fue José María de Cossío quien en 1932 proporcionó parte de la respuesta mostrando que la fuente utilizada por Darío fue la publicación de Pérez Nieva, que califica por su cuenta de «libro de usual manejo» y no acierta a valorar entre la que llama «selva de nuestros Cancioneros cuatrocentistas», ponderando sólo la imitación formal de nuestro poeta y afirma que «el rigor de la imitación (o mejor, calco) estrófica es absoluto» ${ }^{13}$.

La otra parte de la pregunta, sobre la condición de los poetas imitados, está en el propio libro. Y es que Pérez Nieva lleva a cabo una edición parcial del Cancionero de Palacio, operando además con un criterio muy particular. Dedica el libro al rey Alfonso XII, a cuya biblioteca pertenecía entonces y, de todo el amplio conjunto de la que llama poesía «provenzal cortesana» que constituye el cancionero, determina incluir sólo una selección. Aunque todo estaba inédito en su conjunto, como tal libro, decide publicar sólo los poetas de escasa nombradía, cuyas obras no habían sido publicadas. Decisión que basa en un extraño razonamiento, según el cual se trataba de los poetas de la

10. Cleofé Tato, Vida y obra de Pedro de Santa Fe, Noia, Toxosoutos, 1999; «El Cancionero de Palacio (SA7), Ms. 2653 de la Biblioteca Universitaria de Salamanca», en J. L. Serrano (ed.), Cancioneros de Baena. Actas del II Congreso Internacional'Cancionero de Baena', Baena, 2003, I, pp. 495-523; «Prolegómenos a la edición del Cancionero de Palacio (SA7)», en Pilar Lorenzo Gradín y Simone Macerano, El texto medieval. De la edición a la interpretación, Santiago de Compostela, 2012, 299-317; Lucía Mosquera Novoa, Juan de Torres: edición y estudio de su poesía (Tesis doctoral), Universidade da Coruña, 2015.

11. Apud Andrés R. Quintián, op. cit., p. 135.

12. Pedro Henríquez Ureña, «Rubén Darío y el siglo XV», Revue Hispanique, 118 (1920), 324-327.

13. José María de Cossío, «El modelo estrófico de los 'Layes, decires y canciones' de Rubén Darío», Revista de Filología Española, 19 (1932), 283-287. 
clase del pueblo, erudito-populares, por lo que no habían sido editados, y por eso mismo excluía a los magnates y personajes de alta alcurnia, cuyas obras sí habían sido ricamente difundidas: «Ya expusimos antes el criterio que nos sirvió de norma: dar a la estampa la parte desconocida del Cancionero, tomando por base general los poetas de la clase del pueblo, los vates erudito-populares, por lo cual excluimos de este tomo los magnates y personajes de alta alcurnia, muchas de cuyas poesías no son ya inéditas» (p. 307). Esto explica que Darío sólo pueda leer en ese libro a los poetas que Henríquez Ureña calificaba de menos importantes, y no a los Mendozas y Manriques que, por lo demás, sólo aparecen en el cancionero con algún poema juvenil.

Al primero que imita Darío es al poeta Juan de Dueñas. Era este de origen castellano, probablemente palentino, nacido en los primeros años de siglo. Sirvió a Juan II y tuvo desavenencias con su valido Álvaro de Luna, lo que llevó a salir de Castilla y pasar al bando de los infantes de Aragón (a quienes defiende en una composición en respuesta a Íñigo López de Mendoza). Hacia 1429 entra al servicio de don Juan y doña Blanca en la corte de Navarra, donde desempeñará el cargo de maestresala y percibirá diversos pagos. De ese tiempo sería el poema que comienza «Con grant reverencia e mucha mesura», diálogo entre el poeta escudero y la dama que llevan su pleito amoroso ante el propio rey. Después marchará a Italia como soldado siguiendo a Alfonso V en sus campañas, no consta concretamente la de Ponza (1435), pero sí que recibió pagos como uxier d'armes. En Italia compuso sus poemas más famosos y en concreto el titulado Nao de amor, al parecer estando preso en la torre de San Vicente en Nápoles, aunque sería en 1439. A su vuelta de Italia, pasaría un tiempo en Navarra y luego regresaría a Castilla, ya reconciliado con Juan $\mathrm{II}^{14}$.

Dueñas fue, pues, un poeta que alternó la milicia con el verso, conocido en todas las cortes peninsulares y autor de una notable producción, constituida por unas setenta composiciones, en las que alterna la lírica de amores con las disputas poéticas y la sátira política. Aparte escribió dos largos decires, uno alegórico, la Nao de amor, y otro paródico, un contrafactum, la Misa de amores. Los dos decires que imitó Darío corresponden a su etapa juvenil y nos los ha transmitido el Cancionero de Palacio. Son el que comienza «Senyor don Iohan excellente» (fols. 48r-v), que Darío imita en su Dezir (A la manera de Johan de Duenyas): «Reina Venus soberana»; y el que comienza «Entre todos los cuydados» (fols. 146r-v), que imita en Otro dezir: «Ponte el traje azul que

14. Puede verse Juan de Dueñas. La Nao de Amor. Misa de Amores. Ed. de Marco Presotto, Viareggio-Lucca, Mauro Baroni, Col. Agua y Peña, 1997.

Anales, 28 (2016), pp. 171-197 
más» (Véase Anexo, donde reproducimos los poemas del cancionero y los de Rubén).

El primero es un decir de tres estrofas más finida regular (una semiestrofa), estrofas de doce versos en los que se combinan octosílabos y tetrasílabos (el $2^{\circ}$ y $5^{\circ}$ de la primera semiestrofa); son dobles sextillas irregulares: las primeras muestran esa alternancia de versos y dos consonancias, en tanto las segundas son sólo de octosílabos y tres consonancias. El ritmo trocaico dominante alterna también con el dactílico:

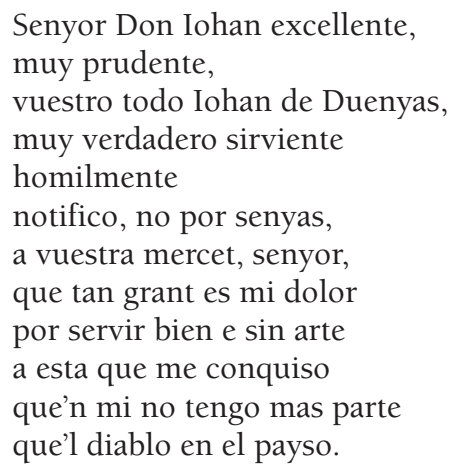

Darío sigue exactamente todos esos pormenores técnicos, aunque haciendo predominar el ritmo dactílico (óo óo ooó o / ooó o / ooó o ooó o / òo ooó oó o), mantiene el sistema de consonancias, aunque lógicamente las cambia (-ente, -eñas, -or, -arte, -iso / -ana, -ones, ino, -or, -ar):

$$
\begin{aligned}
& \text { Reina Venus, soberana } \\
& \text { capitana } \\
& \text { de deseos y pasiones, } \\
& \text { en la tempestad humana } \\
& \text { por ti mama } \\
& \text { sangre de los corazones. } \\
& \text { Una copa me dio el sino } \\
& \text { y en ella bebí tu vino } \\
& \text { y me embriagué de dolor, } \\
& \text { pues me hizo experimentar } \\
& \text { que en el vino del amor } \\
& \text { hay la amargura del mar. }
\end{aligned}
$$

El dezir de Juan de Dueñas viene a ser continuación de un poema anterior en el cancionero, que presenta un diálogo enfrentado entre el poeta-escudero y la dama («Con grant reverencia e mucha mesura»). Ahora, tras aquel debate, el poeta ruega al rey se compadezca de su sufrimiento amoroso e influya para que los jueces Rodrigo de Medina y Ferrant Pérez no dicten sentencia contra él. 
A Rubén Darío le inspira un hermosos poema de amores, que dirige a Venus y envuelve en un manto de sensualidad y mundo pagano de sátiros, copas de vino, besos ardientes, en el que ha proyectado su pasión: «danzo las danzas de ahora / con la música pagana». Como gustaba el poeta medieval, Darío también gusta del juego paronímico de la annominatio («que en el vino del amor / hay la amargura del mar»), o de la expresión paradójica ante la crueldad y rigor de la amada al cerrar el poema: «Bella a quien la suerte avara / ordenara / martirizarme a ternuras». Eran recursos de la vieja poesía amorosa que Darío revive y actualiza poéticamente, y hasta puede que en algún verso, como sugiere José Carlos Rovira, quiera restituir la inspiración marítima del poema Nao de amor de Dueñas ${ }^{15}$

El segundo es un decir de cinco estrofas de siete versos octosilábicos y tres consonancias ( $8 a 8 b 8 a 8 b 8 c 8 c 8 b$ ), sin finida. Técnicamente es mucho más sencillo que el anterior y se ajusta a la forma más simple del decir como sucesión estrófica abierta, que repite en cada estrofa el número de versos, de sílabas y disposición de consonancias. Es un poema de queja al amor, de quien debía haberse guardado y haber escarmentado, pero teme que no sea así, por lo que nunca dirá de esta agua no beberé, pues fuerte cosa es la sed, lo que no impide que proclame la siempre esperanza en su señora. El de Darío es una justa imitación formal y, aunque en el contenido aparentemente nada tiene que ver con el de Dueñas, también es la dama (Mía) el centro del poema y las cinco estrofas una sucesión de encarecimientos engastados en deslumbrantes alusiones mitológicas y eruditas, como muchas veces hacían los poetas cancioneriles en los decires líricos (Anexo).

Otro de los poetas imitados es Juan de Valtierra, seguramente de origen catalán, servidor de Alfonso V de Aragón en torno a la década de 1420-1430. Fue uno de sus oficiales mayores, encargado del avituallamiento de las galeras reales, como consta por los pagos que recibe en Cerdeña o en Valencia. Escribió poesía en castellano y en catalán. El Cancionero de Palacio ha conservado varias composiciones suyas, de las que Pérez Nieva reproduce tres: «Duenya pobre de merçe», «Amor, mi triste partida» y «Enojados de tristura» (fol. 162v), la última de las cuales imita Darío. Como puede verse en el texto del cancionero, se trata de una canción con encabezamiento (cabeza) y tres estrofas, en cada una de las cuales se integra la mudanza y la vuelta. La canción no tiene finida, por lo que la división de última estrofa separando sus tres últimos

15. José Carlos Rovira, «El "clasicismo modernista" de Rubén Darío y la tradición española: su sistematización en Cantos de vida y esperanza», en Rubén Darío. Del símbolo a la realidad. Obra selecta, Madrid, Real Academia Española-Asociación de Academias de la Lengua Española, 2016, pp. 303-336. 
versos por un «Ffin», es absolutamente gratuita. Fue introducida inexplicablemente por Pérez Nieva e induce a error a Darío, que la traslada a su poema. El original de Valtierra es, como decimos, una canción característica de la época y del cancionero. Está constituida por una parte inicial o cabeza, en este caso de cuatro versos (podía variar el número), seguida de tres estrofas, cada una de las cuales está integrada por unos versos de mudanza (en este caso, una redondilla de rima abrazada $a b b a)$ y una vuelta que debe reproducir el mismo número de versos y rima de la cabeza. El esquema sería:

xyyx abbaxyyx cddcxyyx effexyyx,

Darío lo imita perfectamente, aunque incurriendo en el error de transcripción reseñado. El poema de Valtierra es un abierto elogio a la dama, cuya hermosura, gracia y valor encarece sobre las demás criaturas, y a cuya contemplación llama a los enojados de tristura. También el de Darío es una exhibición de la bella desnudez matutina de la amante.

Quizá el más importante de los poetas que imita Rubén sea Pedro de Santa Fe. Su producción poética es relativamente amplia, unos cincuenta poemas, la mayoría en castellano, pero también en gallego y catalán, casi todos transmitidos en el Cancionero de Palacio. Santa Fe nacería a finales del s. XIV, en Aragón. Se le ha venido identificando con el hijo de un célebre converso aragonés llamado Esperaindeo de Santa Fe, aunque ese Pedro de Santa Fe fue condenado a la hoguera en 1499, lo que descartaría por la longevidad a nuestro autor. Desde muy pronto entró como servidor en la corte del rey Alfonso V, aunque no sabemos con qué función, ni si era caballero o escudero. Fue bachiller en artes, quizá por la universidad de Lérida. Junto a otros escritores de la corte y recibiendo ayudas económicas, lo vemos seguir el séquito de Alfonso en las cortes convocadas en Valencia (1417- 1418) y Barcelona (1419). Probablemente desempeñó para el Magnánimo y su biblioteca labores de copista, traductor y comprador de libros (aparece como mediador en una carta del rey a Enrique de Villena pidiéndole las historias de Trogo Pompeyo). Acompañó a Alfonso V en su primer viaje a Italia y Nápoles (1421-1423), como reflejan sus poemas llenos de referencias a aquellas campañas guerreras y de panegírico al monarca. Regresó a España en 1423 y, aunque siempre permaneció al lado de Alfonso, que le concedió una renta vitalicia, ya no le acompañaría en su nuevo viaje de 1432 y toma de Nápoles. No parece que viviera nunca en aquella corte napolitana ${ }^{16}$.

16. Cleofé Tato, Vida y obra..., ob. cit.; la misma autora ha editado y estudiado su poesía, La poesía de Pedro de Santa Fe, Baena, Ayuntamiento de Baena, 2004. 
De Santa Fe imita tres composiciones: una canción que comienza «Senyora, maguer consiento» (fols. 43v-44r), en «Señora, amor es violento»; un loor, posiblemente el que comienza «Rey Alfonso esmerado» (fols. 127v-128v), en « ¿A qué comparar la pura?»; y una copla esparsa «Tanto, senyora, valedes» (fols. 132r-132v), en «¡La gata blanca! En el lecho». La canción es también ahora de tres estrofas, precedidas de una cabeza de cuatro versos octosílabos, el último quebrado. En este caso, los dos últimos versos de la cabeza forman un estribillo o retronx, que se repetirá en las vueltas. Cada estrofa está constituida por cuatro versos de mudanza, que forman una redondilla de rima alterna, y otros cuatro de vuelta, que remiten a la cabeza y repiten parte de ella. En esquema:

8x8y8x4y 8a8b8a8b8x8y8x4y 8c8d8c8d8x8y8x4y 8e8f8f8e8x8y8x4y

Como se advierte, la mudanza de la última estrofa rompe en la redondilla el orden de rima alterna que venía siguiendo la canción para sustituirlo por una rima abrazada ( $8 e 8 f 8 f 8 e$ ). Darío percibe ese fallo técnico y lo corrige en su imitación, regresando a la rima alterna: «Mi gozo tu paladar / rico panal conceptúa, / como en el santo Cantar: / Mel et lac sub lingua tua».

Según resume la rúbrica del cancionero, «Desimulación de la desconexença de m'aymía», el poeta trata de disimular y sobreponerse a la pena de amor que le inflige con su ingratitud (desconexença) su dama aymía y le hace saber que no se engaña. Darío rubrica el suyo «Que el amor no admite cuerdas reflexiones». Y frente a la contención reflexiva del poeta de cancionero, proclama:

$$
\begin{aligned}
& \text { Señora, amor es violento, } \\
& \text { y cuando nos transfigura, } \\
& \text { nos enciende el pensamiento } \\
& \text { la locura. } \\
& \text { No pidas paz a mis brazos } \\
& \text { que a los tuyos tienen presos: } \\
& \text { son de guerra mis abrazos } \\
& \text { y son de incendio mis besos [...]. }
\end{aligned}
$$

El «Lohor al rey Alfonso en la reçepción de Napols» se refiere al recibimiento que el pueblo napolitano hizo a Alfonso y su expedición en julio de 1421, cuando llegó allí tras su periplo por Cerdeña, Córcega y Sicilia. Se alude a la reina Juana II y se anima a Alfonso a proseguir su campaña. Es uno de los siete poemas propagandísticos y de panegírico de Alfonso en su primera campaña italiana. El poema responde a la estructura de un decir de cinco estrofas más finida, estrofas de diez versos, con alternancia de octosílabos y tetrasílabos (en $2,5,7$ y 9), y tres rimas: $8 a 4 a 8 b 8 b 4 b 8 a 4 a 8 c 4 c 8 a$. La finida es regular y 
reproduce la estructura de las primeras semiestrofas. Darío reduce a dos el número de estrofas, mantiene la finida regular y sólo altera ligeramente la rima de la segunda semiestrofa, introduciendo dos rimas nuevas respecto de la primera, con lo que resulta una estrofa de cuatro rimas. En el contenido no tienen nada que ver ambos poemas.

La copla esparsa o esparza es un poema breve, habitualmente de ocho versos, como en este caso, una coplas real de cuatro consonancias. Es un género de poema de procedencia provenzal, cultivado por los poetas catalanes y aragoneses, y también castellanos como el marqués de Santillana. Son breves composiciones en coplas sueltas que desarrollan de manera ligera un pensamiento amoroso. Las primitivas con frecuencia están formadas por una copla y una finida; en general, suelen recurrir a determinados artificios métricos y retóricos, como la repetición verbal, la antítesis o el manzobre. La de Santa Fe responde a la forma más primitiva con tornada, y condensa en sus versos un elogio a la dama, fundamentado simplemente en el recelo que en las demás despierta su valer y virtud. El poema de Darío, igual en la forma, es distinto en el tema, aunque no deja de ser también un poema de elogio y admiración a la amante, que se cierra con una efectista antítesis: «Princesa de mis locuras, / que tus cabellos desatas, / di, ¿por qué las blancas gatas / gustan de sedas obscuras?».

El lay a la manera de Juan de Torres es el último poema imitado. Torres era de origen castellano, posiblemente segoviano, de condición cortesana, que vivió y escribió a mediados del s. XV. Frecuentó la corte de Juan II y perteneció al círculo de don Álvaro de Luna, a quien acompañó en la batalla de Escalona en 1441. Posiblemente viajara a Nápoles y llegara a ser paje de Alfonso V. Allí cobraría fama de poeta y así lo cita Pere Torroellas en su Desconort. Como muestran sus versos mantuvo relaciones con muchos poetas de la época, como don Álvaro (que seguramente lo introdujo en el cancionero), y otros tal vez pertenecientes a aquel grupo: Juan de Padilla, Gonzalo Cuadros, Juan de Silva y Ortiz Calderón.

La imitación de este lay plantea un caso especial, ya que Darío sigue en esta ocasión un texto falso, incorrecto, que no se corresponde con el original. Utiliza, como siempre, la edición de Pérez Nieva, pero este reproduce de forma incompleta el poema de Torres, pues sólo transcribe sus dos primeras estrofas. Los estudios recientes del cancionero y del manuscrito original, en concreto, los realizados por la profesora británica Jane Whetnall, han revelado que en ese lugar se ha producido una alteración del orden de los folios del manuscrito del cancionero, que desplaza el fol. 3 tras el fol. 32, donde continúa 
el poema otras cuatro estrofas ${ }^{17}$. Ese salto de folios no ha sido advertido, como decimos, hasta fechas recientes, por lo que todas las ediciones y prácticamente todos los comentarios sobre el poema lo han considerado constituido únicamente por dos estrofas. En tiempos de Darío, pasaba, pues, por un poema de dos estrofas, que es lo que él imita.

El lay era un tipo de composición de procedencia francesa, muy poco cultivado en la poesía castellana, aunque no faltan referencias a él en el marqués de Santillana y en algún poeta del Cancionero de Baena, como Villasandino. Era un poema lírico (frente al lai narrativo, más conocido), que se difunde particularmente con la poesía de los rhétoriqueurs, de un Guillaume de Machaut, por ejemplo, admirado por nuestros poetas del siglo XV. Era un tipo de poema amoroso, de queja y con gran variedad de metro y estrofa. No hubo de prender apenas en la poesía castellana, pues este de Torres es el único así rubricado y conocido.

El poema de Torres literariamente muestra una composición armoniosa, proporcionada y cerrada. Son seis estrofas de seis versos de seis sílabas cada uno, con dos consonancias por estrofa organizadas en esta secuencia: aabaab $b b c b b c c c d c c d .$. Esto es, coplas capcaudadas, que se van encadenando con la siguiente. Las estrofas no forman unidad de sentido completo, pero la última repite las rimas de la primera, con lo que (además de la reiterada estructura de seis) produce el efecto de un poema cerrado y compacto, apropiado seguramente para el acompañamiento musical.

A manera de conclusión, diríamos que, como ocurrió ya en el momento de su publicación, resulta muy llamativa la incorporación de esta serie de poemas al texto de Prosas profanas y la recreación de la poesía de cancionero por Rubén Darío. Llevado de su gusto por la Edad Media, en este caso busca en unos géneros y estilos poco frecuentados. Con el hallazgo de esta poesía cancioneril, propiciado por la ya comentada publicación de Pérez Nieva, satisface sus propósitos de acercamiento a la tradición literaria española, imitando precisamente unos temas y formas que comparte con la cultura francesa en virtud de sus comunes orígenes provenzales. Por otro lado, Darío hace una elección muy escogida, pues, dentro de la poesía de cancionero, aparte los géneros más convencionales como la canción o el dezir, se decide por formas mucho más minoritarias, como el loor, la esparsa y, sobre todo, el lay, que además recrea de forma equivocada. También los poetas imitados, inducido por la fuente que maneja, seguramente le parecieron más representativos de la

17. Jane Whetnall, «An errant leaf and divided poem: the Lay of Juan de Torres in SA7», en Joseph T. Snow y Roger Wright (eds.), Late Medieval Spanish Studies in honour of Dorothy Sherman Severin, Liverpool, Liverpool University, 2009, pp. 55-73. 
tradición popular hispánica, aunque en realidad se trata de poetas cortesanos y de caballeros al servicio de Juan II de Castilla y de Alfonso V de Nápoles.

\section{Bibliografía citada}

ACereda, Alberto, «Rubén Darío o el proceso creativo de Prosas profanas», Anales de Literatura Hispanoamericana, 28 (1999), 415-430.

Antología de poetas líricos castellanos desde la formación del idioma hasta nuestros días, Madrid, Librería de Perlado, Páez y Cía., 1890-1916, 14 vols.

BARCIA, Pedro Luis, «Prosas profanas y otros poemas», Ibid., pp. 337-375.

Colección de poesías castellanas anteriores al siglo XV, Madrid, Antonio de Sancha, 1779-1790, 4 vols.

Cossío, José María de, «El modelo estrófico de los 'Layes, decires y canciones' de Rubén Darío», Revista de Filología Española, 19 (1932), 283-287.

DARío, RubÉN, «La poesía castellana», en la sección Iniciación melódica, Poesías completas, edición de Alfonso Méndez Plancarte, Madrid, Aguilar, 1968 [1952], pp. 258-267.

- Los Raros, Madrid, Biblioteca Rubén Darío, 1929, p. 160.

- Prosas profanas y otros poemas, Buenos Aires, Imprenta de Pablo E. Coni e Hijos, 1896; Rubén Darío, Prosas profanas y otros poemas, París-México, Librería de la Viuda de C. Bouret, 1901.

DueÑas, Juan de, La Nao de Amor. Misa de Amores. Ed. de Marco Presotto, ViareggioLucca, Mauro Baroni, Col. Agua y Peña, 1997.

GARCÍA ÚNICA, Juan «Un incógnito estigma: la literatura española medieval en Prosas profanas de Rubén Darío», en Ángel Esteban (Coord.), Darío a diario. Rubén y el Modernismo en las dos orillas, Granada, Universidad de Granada, 2007, pp. 71-91.

Henríquez Ureña, Pedro, «Rubén Darío y el siglo XV», Revue Hispanique, 118 (1920), 324-327.

MARTOS, Josep Lluís, «La Real Academia Española y el Cancionero general del siglo XV: un proyecto editorial ilustrado», Boletín de la Real Academia Española, 92 (2012), 221-253.

Mosquera NovoA, Lucía, Juan de Torres: edición y estudio de su poesía (Tesis doctoral), Universidade da Coruña, 2015.

- La poesía de Juan Torres, Alessandria, Edizioni dell'Orso, 2016.

Quintián, Andrés R., Cultura y literatura españolas en Rubén Darío, Madrid, Gredos, 1874, pp. 138-141.

Rovira, José Carlos, «El "clasicismo modernista" de Rubén Darío y la tradición española: su sistematización en Cantos de vida y esperanza», en Rubén Darío. Del símbolo a la realidad. Obra selecta, Madrid, Real Academia EspañolaAsociación de Academias de la Lengua Española, 2016, pp. 303-336. 
Tato, Cleofé, Vida y obra de Pedro de Santa Fe, Noia, Toxosoutos, 1999.

- «El Cancionero de Palacio (SA7), Ms. 2653 de la Biblioteca Universitaria de Salamanca», en J. L. Serrano (ed.), Cancioneros de Baena. Actas del II Congreso Internacional Cancionero de Baena, Baena, 2003, I, pp. 495-523.

- La poesía de Pedro de Santa Fe, Baena, Ayuntamiento de Baena, 2004.

— «Prolegómenos a la edición del Cancionero de Palacio (SA7)», en Pilar Lorenzo Gradín y Simone Macerano, El texto medieval. De la edición a la interpretación, Santiago de Compostela, 2012, 299-317.

VALle-Castillo, Julio, «Prosas profanas y otros poemas: heterogeneidad, intertexto y otros recursos», en Rubén Darío. Del símbolo a la realidad. Obra selecta, Madrid, Real Academia Española-Asociación de Academias de la Lengua Española, 2016, pp. LXXXVII-CIX.

Vendrell de Millás, Francisca, El Cancionero de Palacio (Manuscrito n. 594), Barcelona, CSIC, 1945; Ana Ma Álvarez Pellitero, Cancionero de Palacio, Salamanca, Junta de Castilla y León, 1993.

WhETNALl, Jane, "An errant leaf and divided poem: the Lay of Juan de Torres in SA7», en Joseph T. Snow y Roger Wright, eds., Late Medieval Spanish Studies in honour of Dorothy Sherman Severin, Liverpool, Liverpool University, 2009, pp. 55-73. 
Anexo I: poemas

Otro dezir. Iohan de Duenyas

Senyor Don Iohan excellente, muy prudente,

vuestro todo Iohan de Duenyas,

muy verdadero sirviente

homilmente

notifico, no por senyas,

a vuestra mercet, senyor,

que tan grant es mi dolor

por servir bien e sin arte

a esta que me conquiso

que'n mi no tengo mas parte

que'l diablo en el payso.

Senyor, del grant sentimiento

que yo sento

deveys haver conpasion,

pues padeziendo tormento

soy contento,

esquivo de coraçon

quien sirviendo me da pena; pero, senyor, es tan buena

la que sirvo e tan discreta

que si non soy proveydo

con sentencia inperfecta

del todo sere perdido.

Tomat, senyor, por Dios, estos dos:

a Rodrigo de Medina

e a Ferrant Perez con vos, que confio muy ayna que por mucha de bondat havran de mi piedat.

E si vos, senyor don Iohan, a estos daredes licencia por su mercet no daran contra mi cruel sentencia.

Ffin

Senyor, con gran reverencia, en absencia, ante vos beso la tierra, porque saueis con clemencia su dolencia

del que sirve e no yerra. 
DEZIR

(A la manera de Johan de Duenyas)

Reina Venus, soberana

capitana

de deseos y pasiones,

en la tempestad humana

por ti mana

sangre de los corazones.

Una copa me dio el sino

y en ella bebí tu vino

y me embriagué de dolor, pues me hizo experimentar

que en el vino del amor

hay la amargura del mar.

Di al olvido el turbulento

sentimiento,

y hallé un sátiro ladino

que dio a mi labio sediento

nuevo aliento,

nueva copa y nuevo vino.

Y al llegar la primavera,

en mi roja sangre fiera

triple llama fue encendida:

yo al flamante amor entrego

la vendimia de mi vida

bajo pámpanos de fuego.

En la fruta misteriosa,

ámbar, rosa,

su deseo sacia el labio,

y en viva rosa se posa,

mariposa,

beso ardiente o beso sabio.

¡Bien haya el sátiro griego

que me enseñó el dulce juego!

En el reino de mi aurora

no hay ayer, hoy ni mañana;

danzo las danzas de ahora

con la música pagana.

FFINIDA

Bella a quien la suerte avara

ordenara

martirizarme a ternuras,

dio una negra perla rara

Luzbel para

tu diadema de locuras. 
Dezir que fizo Johan de Duenyas

Entre todos los cuydados

que yo cuytado cuydaua

uno de los olvidados

en que ya menos pensaua

ayer dia de Sant Johan

me renovo tal afan

que la meytat abastaua,

De lo qual mas que de cosa

me fago rnaravellado

segun la pena quexosa

de quando era namorado,

car si yo por bien touiera

escarmentado deuiera

quedar del tienpo pasado.

Car segun el gran pesar

que largo tienpo sofrí

bien me deuiera guardar, poderoso amor, de ti; pero si no me guarde $\mathrm{y}$ algun danyo cobre bien enpleado es en mi.

Que ya tanto me metia en libertat e plazeres que yo, senyor, non temia punto ni mas tus poderes et si por esto padezco yo confieso que merezco tanto mal quanto me dieres. Mas ya quanto bivo sea yo, senyor, nunca dire por turbada que la bea de st agua non venere car fuerte cosa es la set, ante, senyora, mercet de ti sienpre sperare. 


\section{OTRO DEZIR}

Ponte el traje azul que más conviene a tu rubio encanto. Luego, Mía, te pondrás otro, color de amaranto, y el que rima con tus ojos y aquel de reflejos rojos que a tu blancor sienta tanto. En el obscuro cabello pon las perlas que conquistas; en el columbino cuello pon el collar de amatistas, y ajorcas en los tobillos de topacios amarillos y esmeraldas nunca vistas. Un camarín te decoro donde sabrás la lección que dio a Angélica Medoro y a Belkiss dio Salomón; arderá mi sangre loca, y en el vaso de tu boca te sorberé el corazón. Luz de sueño, flor de mito, tu admirable cuerpo canta la gracia de Hermafrodito con lo aéreo de Atalanta; y de tu beldad ambigua la evocada musa antigua su himno de carne levanta. Del ánfora en que está el viejo vino anacreóntico bebe; Febo arruga el entrecejo y Juno arrugarlo debe, mas la joven Venus ríe y Eros su filtro deslíe en los cálices de Hebe. 


\section{CANCIÓN}

Valtierra. Otra.

Enojados de tristura venit, que yo vos daré plazer, servos é mirar e veer una linda creatura. De muy nueva alegría alegra a los que la veen, en veyendo, luego creen que mereçe señoría. Mirando su hermosura créceles seso, saber con que puedan conoçer todo el bien que en ella atura. ¡Qué graçia e valor muestra su gesto donoso! el mirar muy agradosso lleno de mucho amor. Muchos cabos si atura quiérenla obedecer, ¿quién se poría tener que hallasse tal ventura? Reina es de las mejores e del mundo más amada, donosa, muy asesada, quita de vanos amores Dios d'amor d'otra non cura. Bien lo muestra su poder, pues la haze floreçer sobre todas sin mesura.

\section{(a la manera de Valtierra)}

Amor tu ventana enflora, y tu amante esta mañana preludia por ti una diana en la lira de la Aurora. Desnuda sale la bella y del cabello el tesoro pone una nube de oro en la desnudez de estrella; y en la matutina hora de la clara fuente mana la salutación pagana de las náyades a Flora. En el baño al beso incita sobre el cristal de la onda la sonrisa de Gioconda en el rostro de Afrodita; y el cuerpo que la luz dora, adolescente, se hermana con las formas de Diana, la celeste cazadora. Y mientras la hermosa juega con el sonoro diamante, más encendido que amante el fogoso amante llega a su divina señora. FFIN

Pan, de su flauta desgrana un canto que, en la mañana, perla a perla, ríe y llora. 
Santa Fe. Desimulacion de la desconexença de m'aymia

Senyora, maguer consiento

e quiero sofrir mi danyo,

mas, pensat, por sentimiento

no m' enganyo.

Senyora, si penedir

a todos bien pareçiese,

hora es que'l buen servir

en ta vos lo defendiese,

por celar lo qu'en vos siento

ensuenyo que no m'ensayo;

mas, pensat, por sentimiento

no m'enganyo,

Si de mi mal conocer

hosase tomar vengança,

diria que retrayer

me faze de vuestra usança,

pero cubre mi tormento

e so contra mi estranyo;

mas, pensat, por sentimiento

no m'enganyo.

Sino que's fuerte quitar

la fe de los muy leales

quanto por vuestras senyales

ya devria renunciar

por no mostrar ronpimiento

sigo los tiempos del anyo;

mas, pensat, por sentimiento

no m'enganyo. 


\section{QUE EL AMOR NO ADMITE CUERDAS REFLEXIONES \\ (A la manera de Santa Ffe)}

Señora, amor es violento, y cuando nos transfigura nos enciende el pensamiento la locura.

No pidas paz a mis brazos que a los tuyos tienen presos: son de guerra mis abrazos y son de incendio mis besos; y sería vano intento el tornar mi mente obscura si me enciende el pensamiento la locura.

Clara está la mente mía de llamas de amor, señora, como la tienda del día o el palacio de la aurora.

$\mathrm{Y}$ al perfume de tu ungüento te persigue mi ventura, y me enciende el pensamiento la locura.

Mi gozo tu paladar rico panal conceptúa, como en el santo Cantar: Mel et lac sub lingua tua. La delicia de tu aliento en tan fino vaso apura, y me enciende el pensamiento la locura. 
Lohor al Rey Alfonso en reçepcion de Napols. Santa Fe

Rey Alfonso esmerado, non dubdado

en nobleza sostener,

con virtut mas que poder

en prender:

¿qual rey fue tan acabado?

Hordenado

fue por Dios venir aqui

pues anssi

vos ha el pueblo adorado,

En este noble regnado,

demandado

non fue Rey con tanto amor:

el chico fasta'l mayor

con ardor,

an vuestras manos besado.

Trebaxado

tu buscar, rey, con andançia,

e por gracia

otro tal lo an cobrado.

El gran Çipion triado,

alongado

de viçio et de viltat, no a, con tanta beldat, humildat:

el bien comun defensado,

el popular tribulado,

e madama en fortuna,

de laguna

los avredes delibrado. 
Mucho vos es obligado

e ligado

este pueblo con razón

quan muxer, regno y nación,

en tal sazon,

queredes aver lexado.

Rey como vos, eredado

non dubdar regno strangero,

cavallero

podedes ser llamado.

Pus ansi s'es entregado

el poblado

d'estas partes sin pensar

devedes abreviar

reçuçitar

sin cuerpo medio finado;

después, visitat de grado

las provincias de SignoIo

donde solo

bivredes aconpanyado.

Ffin

El peso glorificado

de buen grado

ordene de su gran polo,

mas que Apolo

vos dé saber acabado. 


\section{LOOR}

(A la manera del mismo.)

¿A qué comparar la pura

arquitectura

de tu cuerpo? ¿A una sutil

torre de oro y marfil?

¿O de Abril

a la loggia florecida?

Luz y vida

iluminan lo interior,

y el amor

tiene su antorcha encendida.

Quiera darme el garzón de Ida

la henchida

copa, y Juno la oriental

pompa del pavón real,

su cristal

Castalia, y yo, apolonida,

la dormida

cuerda haré cantar por la

luz que está

dentro de tu cuerpo prendida.

La blanca pareja anida

adormecida:

aves que bajo el corpiño

ha colocado el dios niño,

rosa, armiño,

mi mano sabia os convida

a la vida.

Por los boscosos senderos

viene Eros

a causar la dulce herida.

FFIN

Señora, suelta la brida

y tendida

la crin, mi corcel de fuego

va; en él llego

a tu campaña florida. 
Copla esparça. Santa ffe

Tanto, senyora, valedes que las damas virtuosas biven de vos rezelosas que la fama les robedes. A toda muger que val si se plaz façer buen fecho para non errar el trecho tome a vos por senyal.

\section{Tornada}

Si qual con ssi parcial a de tal oyr despecho mas prueva vuestro drecho su invidia cryminal.

\section{COPLA ESPARÇA}

\section{(A la manera del mismo)}

¡La gata blanca! En el lecho maya, se encorva, se extiende.

Un rojo rubí se enciende sobre los globos del pecho.

Los desatados cabellos

la divina espalda aroman.

Bajo la camisa asoman dos cisnes de negros cuellos TORNADA LIBRE

Princesa de mis locuras, que tus cabellos desatas, di, ¿por qué las blancas gatas gustan de sedas obscuras? 
Lay de Iohan de Torres

Ay triste de mi por que padesci sin lo meresçer

Pues siempre seruy leal fast'aquí a mi entender

A quien su saber ya non puede ser me faze pensar

Que sin su querer ya non puede ser sin mucho pesar.

Por que de llorar e de sospirar ya non cesare.

Lo que desee et deseare ya mas todauia

Aunque cierto se que menos avre qu'en el primer dia.

De quien su porfia me quita alegría después que la vi.

Que ya mas querria morir algún dia que beuir ansi.

Las pues presomi que desque nasçi por ti padesçer.

\section{LAY}

Torres. Lay

(A la manera de Johan de Torres)

Ay triste de mi Porque padesçi

¿Qué pude yo hacer

para merecer

Sin lo meresçer. la ofrenda de ardor

de aquella mujer

Pues siempre serbi

Leal hasta aquí

a quien, como a Ester,

maceró el Amor?

A mi entender.

Intenso licor,

A quien su saber Ya non puede ser Me haze pensar

Que sin su querer Ya non puede ser Sin mucho pesar. perfume y color

me hiciera sentir

su boca de flor;

dile el alma por

tan dulce elixir.

(Los poemas del cancionero están transcritos de la edición digitalizada del Cancionero de Palacio, Biblioteca Universitaria de Salamanca, Ms. 2653: http://hdl.handle. net/10366/81629)

Los poemas de Rubén Darío están copiados de Revista Nueva, 1 (1899), 626-630 y 673-675).

Anales, 28 (2016), pp. 171-197 